2007-01-01

\title{
Human Papillomavirus Prevalence and Genotypes in an Opportunistically Screened Irish Female Population
}

\author{
Helen Keegan \\ Technological University Dublin, helen.keegan@tudublin.ie \\ Fergus Ryan \\ Technological University Dublin, fergus.x.ryan@tudublin.ie \\ Alison Malkin \\ Technological University Dublin, alison.malkin@tudublin.ie
}

See next page for additional authors

Follow this and additional works at: https://arrow.tudublin.ie/scschbioart

Part of the Virology Commons

\section{Recommended Citation Science,64(1), p.18-22. doi:10.1080/09674845.2007.11732750 \\ This Article is brought to you for free and open access by the School of Biological Sciences at ARROW@TU Dublin. It has been accepted for inclusion in Articles by an authorized administrator of ARROW@TU Dublin. For more information, please contact arrow.admin@tudublin.ie, aisling.coyne@tudublin.ie,gerard.connolly@tudublin.ie. Funder: Strand III}

Keegan,H.,Ryan, F., Malkin, A.,Griffin, M., Lambkin, H. (2007). Human papillomavirus prevalence and genotypes in an opportunistically screened Irish female population. British Journal of Biomedical

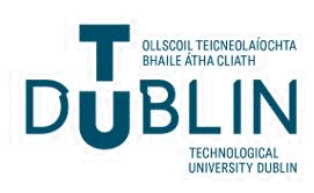




\section{Authors}

Helen Keegan, Fergus Ryan, Alison Malkin, Mairead Griffin, and Helen Lambkin

This article is available at ARROW@TU Dublin: https://arrow.tudublin.ie/scschbioart/65 
Antenna \& High Frequency Research Centre

\title{
Articles
}

Dublin Institute of Technology

Year 2007

\section{Human papillomavirus prevalence and genotypes in an opportunistically screened Irish female population}

\author{
Helen Keegan* $\quad$ Fergus Ryan Dr. ${ }^{\dagger} \quad$ Alison Malkin ${ }^{\ddagger}$ \\ Mairead Griffin** Helen Lambkin ${ }^{\dagger \dagger}$
}

*Dublin Institute of Technology

${ }^{\dagger}$ Dublin Institute of technology, fergus.x.ryan@dit.ie

${ }^{\ddagger}$ Dublin Institute of Technology

** St. James' Hospital

${ }^{\dagger \dagger}$ Dublin Institute of Technology

This paper is posted at ARROW@DIT.

http://arrow.dit.ie/ahfrcart/1 


\section{— Use Licence}

\section{Attribution-NonCommercial-ShareAlike 1.0}

You are free:

- to copy, distribute, display, and perform the work

- to make derivative works

Under the following conditions:

- Attribution.

You must give the original author credit.

- Non-Commercial.

You may not use this work for commercial purposes.

- Share Alike.

If you alter, transform, or build upon this work, you may distribute the resulting work only under a license identical to this one.

For any reuse or distribution, you must make clear to others the license terms of this work. Any of these conditions can be waived if you get permission from the author.

Your fair use and other rights are in no way affected by the above.

This work is licensed under the Creative Commons Attribution-NonCommercialShareAlike License. To view a copy of this license, visit:

- URL (human-readable summary):

http://creativecommons.org/licenses/by-nc-sa/1.0/

- URL (legal code):

http://creativecommons.org/worldwide/uk/translated-license 


\section{Human papillomavirus prevalence and genotypes in an opportunistically screened Irish female population}

H. KEEGAN**, F. RYAN*, A. MALKIN*, M. GRIFFIN ${ }^{\star}$ and $H$. LAMBKIN

'Molecular Pathology Research Laboratory, Coombe Women's Hospital; 'School of Biological Sciences, Dublin Institute of Technology; and 'Department of

Histopathology, St. James' Hospital. Dublin, Ireland

Accepted: 16 February 2007

\section{Introduction}

Human papillomavirus (HPV) infection causes benign and malignant neoplastic lesions of the uterine cervical epithelium. Multiple HPV types are known to infect the anogenital region and these are classified as high-risk or lowrisk according to their oncogenic potential.' High-risk types 16 and 18 are the most common HPV types found in cervical carcinomas worldwide and much research has focused on these HPV types in the elucidation of the molecular mechanisms of cervical carcinogenesis. ${ }^{2}$ The majority of cervical HPV infections are of high-risk type; however, the geographical distribution of HPV types other than HPV 16 and 18 varies considerably world wide. ${ }^{3}$

Human papillomavirus is a ubiquitous organism and it is estimated that approximately $80-85 \%$ of individuals will be infected during their lifetime.' Human papillomavirus infections, most of which are transient, are most common in young adults and persistent high-risk infection is the single most important risk factor in the development of cancerous and precancerous lesions. ${ }^{5,6}$

Precancerous cervical lesions are screened for by conventional Papanicolaou (Pap) smear examination and most developed countries have screening programmes in place. Recently, however, there has been a drive towards DNA-based testing for high-risk HPV as part of screening algorithms, as this substantially increases the sensitivity of detection of neoplasia. ${ }^{--4}$

The Republic of Ireland is currently awaiting the full implementation of a national cervical screening programme, which has been piloted in one region of the country since 2000. Few data are available on HPV prevalence in the normal asymptomatic Irish female population, and thus the aim of the current study is to determine the prevalence of genital HPV infection in women presenting for opportunistic cervical screening. In the study, HPV prevalence and genotype are determined using a multiplex

Correspondence to: Dr. Helen Keegan

Email:keeganh28@yahoo.com

\section{ABSIRACI}

This study aims to evaluate human papillomavirus (HPV) prevalence and predominating genotypes in liquid-based cervical cytology samples from an Irish urban female population. In addition to use of routine cervical cytology testing, women are screened for HPV using the MY09/11 primers for the HPV L1 gene and primers for B-globin amplification in a multiplex format. Overall, 996 women between the ages of 16 and 72 years (average age: 35 ) are included in the study and HPV prevalence was $19.8 \%$. Cytology results showed that $88.9 \%$ were normal, $9 \%$ borderline or mild dyskaryosis, $1.1 \%$ moderate dyskaryosis and $0.9 \%$ severe dyskaryosis. Human papillomavirus prevalence in women under 25 was $31 \%$, reducing to $23 \%$ in women in the 25-35 age group and to $11 \%$ in women over 35. Human papillomavirus prevalence increased with grade of cytology from $11.4 \%$ (normal) through 85.4\% (borderline), $84 \%$ (mild), $100 \%$ (moderate) to $100 \%$ (severe dyskaryosis). HPV $16(20 \%)$ and $18(12 \%)$ were the most common high-risk types detected in the study. Other common high-risk types were (in descending onder) HPV $66,33,53,31$ and 58. HPV 66 was associated with the detection of borderline abnormalities by cytology. This is the first population-based study of HPV prevalence in the normal healthy cervical screening population in the Republic of Ireland.

\section{KEY WORDS: Cenix dysplasia.}

Genotype.

Human papillomavirus.

Prevalence.

Urban health.

polymerase chain reaction (PCR) technique, followed by HPV L1 gene sequencing.

\section{Materials and methods}

Sample collection and subjects

Cervical PreservCyt specimens were obtained from women attending their local general practitioner (GP) in the Dublin area for cervical smear testing. Women were invited to participate in the study by their GP and 996 samples were obtained with informed consent between 2004 and 2005 (age range: $16-72$ years, mean: 35 years). Following preparation of a ThinPrep slide and cytological examination, results were coded as normal, borderline or by grade of dyskaryosis 
Table 1. Distribution of HPV prevalence according to age and cytology result $(n=996)$.

\begin{tabular}{|c|c|c|c|c|c|c|c|}
\hline \multirow[t]{3}{*}{ Crtology } & \multicolumn{7}{|c|}{ Age of women (yoers) and HPV status } \\
\hline & \multicolumn{2}{|c|}{$<25$} & \multicolumn{2}{|c|}{$25-30$} & \multicolumn{2}{|c|}{$>35$} & \multirow[b]{2}{*}{ Total } \\
\hline & HPV+ & HPV- & HPV+ & HPV- & HPV+ & HPV- & \\
\hline Normal & 27 & 122 & 48 & 301 & 26 & 362 & 886 \\
\hline Bondertine" & 10 & 2 & 17 & 4 & 8 & 0 & 41 \\
\hline Mild" & 13 & 5 & 22 & 2 & 6 & 1 & 49 \\
\hline Moderate't & 6 & 0 & 3 & 0 & 2 & 0 & 11 \\
\hline Severe' & 2 & 0 & 4 & 0 & 3 & 0 & 9 \\
\hline Total & 58 & 129 & 94 & 307 & 45 & 363 & 996 \\
\hline
\end{tabular}

Borderline nuclear chan including atypical gandular and squamous cells of undetermined significance.

'Grede of cenical dyskanyosis.

(mild, moderate or severe). Residual PreservCyt material was used for determination of HPV prevalence and genotype.

\section{Human papillomavirus detection}

PreservCyt specimens $(4 \mathrm{~mL})$ were centrifuged at $3000 \times 8$ and the resulting pellets washed $(x 2)$ in Tris-EDTA buffer (10 $\mathrm{mmol} / \mathrm{L}$ Tris, $1 \mathrm{mmol} / \mathrm{L}$ EDTA $/ \mathrm{pH} 8.0]$ ). Extraction of DNA was performed using the QIAamp DNA mini kit (Qiagen, UK), following the manufacturer's instructions. Detection of HPV was performed using the MY09/11 consensus primers for amplification of a region of the $L 1$ gene and with primers for amplification of a region of the $\beta$-globin housekeeping gene, in a multiplex format, as described previously."

\section{Human papillomavirus genotyping}

Human papillomavirus-positive samples $(n=132)$ were genotyped by a direct sequencing approach using the MY09/11 product of the L1 gene." MY09/11 PCR was optimised so that the reaction mix contained $12.5 \mu \mathrm{L}$ DNA, $10 \mathrm{pmol}$ each of the forward and reverse primers, $200 \mu \mathrm{mol} / \mathrm{L}$ deoxynucleoside triphosphates, 1x PCR buffer (containing $10 \mathrm{mmol} / \mathrm{L}$ Tris $\mathrm{HCl}[\mathrm{pH} 8.3], 50 \mathrm{mmol} / \mathrm{L} \mathrm{KCl}), 2 \mathrm{mmol} / \mathrm{L}$ $\mathrm{MgCl}_{2}$ and 1 unit of Platinum Thermus aquaticus (Taq) DNA polymerase (Invitrogen.) in a final volume of $50 \mu \mathrm{L}$.

The PCR was initiated by a $5 \mathrm{~min}$ denaturation and enzyme activation step at $95^{\circ} \mathrm{C}$, followed by 35 cycles of $1 \mathrm{~min}$ at $95^{\circ} \mathrm{C}, 1 \mathrm{~min}$ at $57^{\circ} \mathrm{C}$ and $1 \mathrm{~min}$ at $72^{\circ} \mathrm{C}$, and completed by a $5 \mathrm{~min}$ extension step at $72 \mathrm{C}$. Products were visualised by electrophoresis of $5 \mu \mathrm{L}$ of the reaction on a $1 \%$ agarose gel.
To remove excess primers, dNTPs and enzyme the MY09/11 PCR products ( $450 \mathrm{bp}, 45 \mu \mathrm{L}$ ) were purified using the GenElute PCR Clean-Up kit (Sigma-Aldrich). Products were then concentrated by vacuum drying with centrifugation. Samples were sequenced using the forward MY11 degenerate primer at a concentration of $60 \mathrm{pmol} / \mu \mathrm{L}$. HPV genotype was determined following BLAST (www.ncbi.nlm.nih.gov) analysis of sequences.

\section{Statistical analysis}

Statistical significance of the relationship of HPV status to age and abnormal cytology was determined by the Pearson $\chi^{2}$ test. All statistics were performed using SPSS v.11 software (SPSS Inc.).

\section{Results}

Of the 996 samples analysed by cytology, $11.1 \% \quad(n=110)$ showed some degree of cytological neoplastic abnormality. The majority of women presenting for cervical screening were aged over 25; however, the prevalence of cervical abnormalities was greatest in those aged under 25 years (Table 1).

Human papillomavirus DNA was detected in 197 (19.8\%) of the 996 samples tested. (Table 2). Human papillomavirus infection was strongly associated with abnormal cytology $(P<0.0001)$ and was $100 \%$ sensitive for the identification of samples with high-grade lesions. Human papillomavirus infection was associated with borderline cytology and lesions $(P<0.0001)$.

Table 2. HPV status and cytology result $(n=996)$

\begin{tabular}{|c|c|c|c|c|c|c|c|}
\hline \multirow{2}{*}{\multicolumn{2}{|c|}{ HPV Status }} & \multicolumn{6}{|c|}{ Convical cytology } \\
\hline & & Normal & Abnormar & Borderline' & Mild* & Moderated & Severet \\
\hline Positive & $(n=197)$ & 101 (51.3\%) & $96(48.7 \%)$ & 35 (17.8\%) & $41(20.8 \%)$ & $11(5.6 \%)$ & $9(4.6 \%)$ \\
\hline Negative & $(n=799)$ & 785 (98.2\%) & 14 (1.8\%) & $6(0.8 \%)$ & $8(1.0 \%)$ & $0(0 \%)$ & $O(0 \%)$ \\
\hline Total & $(n=996)$ & 886 & 110 & 41 & 49 & 11 & 9 \\
\hline
\end{tabular}

Classified as elther borderline cytology or dyskanyosis.

'Bonderline nuclear chenges, including atypical glandular and squamous cells of undetermined sienificance.

Grade of dyskanyosis. 


\section{Human papillomavirus prevalence and age}

The breakdown of HPV prevalence by age is shown in Table 1. Cumulatively, 77\% (152/197) of HPV infections occurred in those aged under 35 . In those aged over 35, 19\% $(38 / 197)$ prevalence was seen in women aged $36-49$ years, and $4 \%(7 / 197)$ in women aged over 50 years. Prevalence decreased with age. The trend of decreasing HPV prevalence with age was highly significant $(P<0.0001)$. Of the $101 \mathrm{HPV}$-positive cases with normal cytology, 75 (74\%) were in women under the age of 35 years.

\section{Human papillomavirus genotype prevalence}

Genotyping of 132 HPV-positive samples was performed by sequencing the MY09/11 HPV L1 gene PCR product. Overall, 20 different HPV genotypes were identified. The most common genotypes (in descending order) were $16,18,66,33$, (53 and 6), 61, (70, 31 and 58), 83, (81, 62, and 68), (59 and 54), and (73, 52, 11, 84 and 88) (Fig. 1). The most common highrisk types were 16 and 18 , and the most common low-risk types were 6 and 61 .

High-risk HPV genotypes predominated (74\%) and overall there was a higher frequency of high-risk types than low-risk types for each cytology grade. High-risk HPV types $16,18,66,33,53,31$ or 58 were found in $49 / 66(74 \%)$ of abnormal cytology samples and $10 / 12(83 \%)$ of samples with high-grade lesions.

Analysis of HPV genotype and cytology revealed that HPV 16 was the most common type both in mild dyskaryosis (29\%) and in samples with moderate or severe dyskaryosis $(33 \%)$. In those cases with borderline cytology, HPV 66 predominated. In samples with normal cytology, HPV 16 and 18 were the most common HPV types.

\section{Discussion}

The aim of the present study is to provide an analysis of the cytological and HPV status of Irish women undergoing opportunistic cervical screening in an urban setting. In this study, $11 \%$ of women presenting for opportunistic screening had an abnormal smear result, consisting of $4 \%$ borderline nuclear change, $5 \%$ mild, $1 \%$ moderate and $1 \%$ severe dyskaryosis. A similar rate of $10 \%$ abnormal cytology has been reported previously in the United Kingdom, with approximately $3 \%$ borderline, $4 \%$ low-grade dyskaryosis and $3 \%$ high-grade dyskaryosis. ${ }^{12}$

Cervical abnormalities in Irish women, particularly those with high-grade lesions, have been reported previously to be more common in women under 25 years of age and their prevalence within this group is thought to be increasing. ${ }^{13}$ Currently, the American Cancer Society recommends cervical screening for women within three to five years of commencement of sexual activity and no later than at 21 years of age," while results from a longitudinal study conducted by the Icelandic Cancer Society between 1979 and 2002 on the development of high-grade lesions indicate that screening should start before the age of 25 , with a maximum three-year screening interval. ${ }^{15}$

In the Republic of Ireland, cervical screening is currently recommended for women over the age of 25 years and the proposed Irish Cervical Screening Programme plans to offer free cervical screening to women aged 25-60 (www.icsp.ie). Findings of the present study suggest that introducing Irish

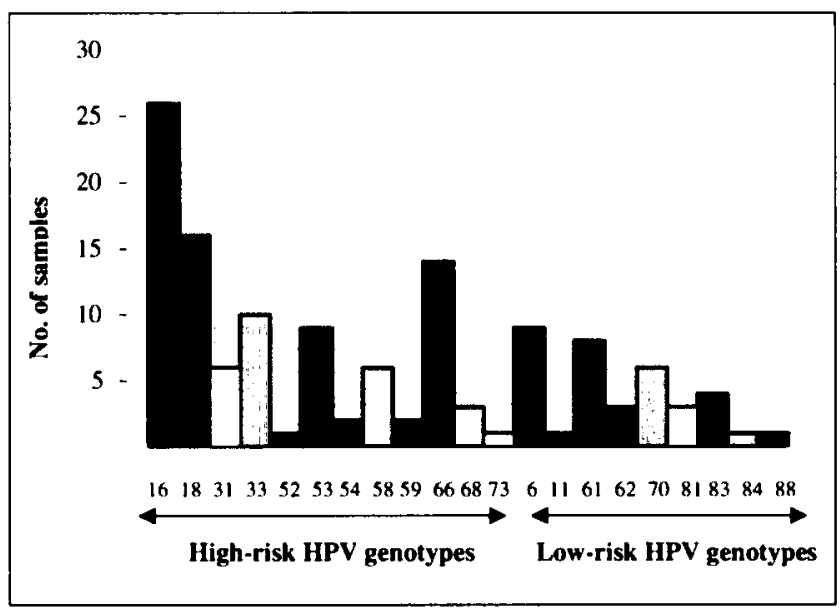

Fig. 1. Prevalence of HPV genotypes.

women to the cervical screening system before the age of 25 may be beneficial and may identify those at risk of developing later abnormalities.

Human papillomavirus prevalence in the present study was $19.8 \%$. In the UK a similar prevalence rate of $20 \%$ was detected, ${ }^{12}$ while in Italy, in a similar urban population, a prevalence of $16 \%$ was detected, also using consensus HPV detection methods. ${ }^{\text {in }}$

Great variation in prevalence figures for total HPV infection has been reported worldwide. A recent IARC study, which surveyed 10 population-based studies on approximately 15,000 samples from four continents, showed that the prevalence of HPV infection varied greatly $(2 \%-30 \%)^{2}$

Several studies report high HPV prevalence in young women, with a decrease in prevalence with age. ${ }^{\mid+1 x}$ In the present study, HPV prevalence decreased with age, from $31 \%$ in those aged under 25 years to $23 \%$ in the $25-35$ age group to $11 \%$ in those aged over 35 .

It has been shown previously that HPV testing has a high sensitivity for the detection of high-grade lesions, ${ }^{14}$ and most studies demonstrate the high negative predictive value of HPV testing in primary screening. ${ }^{2022}$ In a similar population-based HPV prevalence study using consensus primers, HPV was found in $12.7 \%$ of the negative cytology cases, $85 \%$ of borderline cases, $96 \%$ of mild abnormalities and $94 \%$ of high-grade disease..$^{2}$ The present study reports similar prevalences rates in these cytological categories.

This is the first Irish study to generate population-based HPV genotype prevalence data. To date, three other HPV genotyping studies have been performed in Ireland. One involved genotypic mapping of cervical adenocarcinomas, ${ }^{23}$ while the others correlated HPV status with cellular biomarkers predictive of squamous and glandular preinvasive lesions. ${ }^{24.24}$

While the direct sequencing approach used in the present study cannot identify multiple HPV infections, the dominant HPV infection present at the cervix can be identified. In the present study, high-risk HPV types predominated in all grades of cytology, and confirms the findings of other studies. ${ }^{2,27}$ Human papillomavirus types 16 and 18 were the most common high-risk types detected in the present study, with prevalences of $20 \%$ and $12 \%$, respectively, while, HPV $6(7 \%)$ was the most common lowrisk type. Other recent European population-based HPV 
typing studies also report a predominance of HPV 16 infection, but prevalence of HPV types other than HPV 16 varied. ${ }^{24.24}$

Interestingly, the third most common HPV type detected in this Irish cohort was HPV 66, which has not been reported previously in Irish HPV genotyping studies. However, this may be a consequence of using typing methods that do not identify a wide range of HPV types. Other studies in which HPV 66 has been detected have involved the use of the line-probe assay ( $\mathrm{LiPa}$, Roche Biochemicals) or direct sequencing of consensus HPV PCR products. ${ }^{30.31}$ In these studies, HPV 66 was detected at moderate frequencies of $2 \%$ and $4 \% .^{28,24}$

In a study by Melchers et al., conducted in The Netherlands, which used the LiPa assay and sequencing to identify HPV types in various grades of cytology, HPV 66 was the second most common high-risk type identified. ${ }^{31}$ In the study, HPV 66 was associated with abnormal cytology and was found in women with borderline cytology, lowgrade lesions and high-grade lesions, but was most common in the borderline group. In the present study, 10/14 cases of HPV 66 identified occurred in women under the age of 30 years, and all but three cases of HPV 66 were associated with abnormal cytology.

More recently, HPV 66 was the fourth most common HPV type identified at a frequency of $6 \%$ in a university population in Rome, ${ }^{31}$ and it was the fourth most common HPV type detected in a high-risk Spanish population."

This highlights the need for population-based HPV typing studies before decisions are made on HPV screening using commercial systems, which may not cover the most common high-risk types in a given population. Other studies have highlighted the need for a full evaluation of HPV type distribution in a given population, particularly with regard to the development of vaccines against high-risk types other than HPV 16. ${ }^{12.33}$ It is hoped to determine the effects of multiple HPV types in the Irish population using the LiPa assay in a future study.

The present study suggests that if HPV testing is to be used as part of a screening algorithm then preliminary HPV genotyping studies that facilitate multiple type detection should be performed to determine the impact of high-risk HPV types other than 16 and 18 in a given population.

The authors wish to thank the women and general practitioners who participated in the study. They would also like to thank the staff of the Cytology Laboratory, Department of Histopathology, St. James' Hospital, Dublin, and Dr. John Kearney of Dublin Institute of Technology, for assistance with sample collection and statistical analyses, respectively. This work was funded by the Technological Sector III grant of the National Development Plan and by the Research Support Unit, Dublin Institute of Technology, Ireland.

\section{References}

1 de Villiers EM, Fauquet C, Broker TR, Bernard HU, zur Hausen H. Classification of papillomaviruses. Virology 2004; 324: 17-27.

2 Franceschi S. The IARC commitment to cancer prevention: the example of papillomavirus and cervical cancer. Recent Results Cancer Res 2005; 166: 277-97.

3 Munoz N, Bosch FX, de Sanjose S et al. Epidemiologic classification of human papillomavirus types associated with cervical cancer. N Engl J Med 2003; 348: 518-27.

4 Jenkins D, Sherlaw-Johnson C, Gallivan S. Can papilloma virus testing be used to improve cervical cancer screening? Int I Cancer 1996; 65: 768-73.

5 Syrjanen S, Shabalova I, Petrovichev $N$ et al. Factors predicting persistence of high-risk human papillomavirus (HPV) infections in women prospectively followed-up in three new independent states (NIS) of the former Soviet Union. Eur J Gynaecol Oncol 2005; 26: 491-8.

6 Snijders PJ, Steenbergen RD, Heideman DA, Meijer C]. HPVmediated cervical carcinogenesis: concepts and clinical implications. J Pathol 2006; 208: 152-64.

7 Yarkin F, Chauvin S, Konomi N et al. Detection of HPV DNA in cervical specimens collected in cytologic solution by litigationdependent PCR. Acta Cytol 2003; 47: 450-6.

8 Cuzick J, Szarewski A, Cubie $\mathrm{H}$ et al. Management of women who test positive for high-risk types of human papillomavirus: the HART study. Lancet 2003; 362: 1871-6.

9 Clavel C, Cucherousset J, Lorenzato $M$ et al. Negative human papillomavirus testing in normal smears selects a population at low risk for developing high-grade cervical lesions. Br J Cancer 2004; 90: 1803-8.

10 Keegan H, Malkin A, Ryan F et al. Validation of a multiplex PCR assay for the simultaneous detection of human papillomavirus and Chlamydia trachomatis in cervical PreservCyt samples. Clin Chem 2005; 51: 1301-2.

11 Ortiz M, Torres $M$, Munoz $L$ et al. Oncogenic human papillomavirus (HPV) type distribution and HPV type E6 variants in two Spanish population groups with different levels of HPV infection risk. J Clin Microbiol 2006; 44: 1428-34.

12 Cuschien KS, Cubie HA, Whitley MW et al. Multiple high-risk HPV infections are common in cervical neoplasia and young women in a cervical screening population. J Clin Pathol 2004; 57: 68-72.

13 Treanor D, Magee D, Turner L, Carroll B, Gibbons D. Incidence of cervical dyskaryosis in Ireland: report of a five-year audit. Ir Med J 2002; 95: 206-8.

14 Moscicki AB. Cervical cytology testing in teens. Curr Opin Obstet Gynecol 2005; 17: 471-5.

15 Sigurdsson $\mathrm{K}$, Sigvaldason $\mathrm{H}$. Longitudinal trends in cervical histological lesions (CIN 2-3+): a 25-year overview. Acta Obstet Gynecol Scand 2006; 85: 359-65.

16 Centurioni MG, Puppo A, Merlo DF et al. Prevalence of human papillomavirus cervical infection in an Italian asymptomatic population. BMC Infect Dis 2005; 5 : 77.

17 Matos E, Loria D, Amestoy GM et al. Prevalence of human papillomavirus infection among women in Concordia, Argentina: a population-based study. Sex Transm Dis 2003; 30: 593-9.

18 Beby-Defaux A, Bourgoin A, Ragot $S$ et al. Human papillomavirus infection of the cervix uteri in women attending a health examination center of the French social security. I Med Virol 2004; 73: 262-68

19 Bigras G, de Marval F. The probability for a Pap test to be abnormal is directly proportional to HPV viral load: results from a Swiss study comparing HPV testing and liquid-based cytology to detect cervical cancer precursors in 13,842 women. Br J Cancer 2005; 93: 575-81.

20 Cuzick J, Beverley E, Ho L et al. HPV testing in primary screening of older women. Br / Cancer 1999; 81: 554-8.

21 Cuzick J, Sasieni P, Davies P et al. A systematic review of the role of human papillomavirus (HPV) testing within a cervical 
screening programme: summary and conclusions. $\mathrm{Br} /$ Cancer 2000; 83: 561-5.

22 Rozendaal L, Westerga J, van der Linden JC et al. PCR-based high-risk HPV testing is superior to neural network based screening for predicting incident CIN III in women with normal cytology and borderline changes. J Clin Pathol 2000; 53: 606-11.

23 O'Leary JJ, Landers RJ, Crowley $\mathrm{M}$ et al. Genotypic mapping of HPV and assessment of EBV prevalence in endocervical lesions. J Clin Pathol 1997; 50: 904-10.

24 Murphy N,Ring M, Killalea AG et al. p16INK4A as a marker for cervical dyskaryosis: CIN and CGIN in cervical biopsies and ThinPrep smears. J Clin Pathol 2003; 56: 56-63.

25 Murphy N, Ring M, Heffron CC et al. p16INK4A, CDC6, and MCM5: predictive biomarkers in cervical preinvasive neoplasia and cervical cancer. I Clin Pathol 2005; 58: 525-34.

26 Riethmuller D, Gay C, Bertrand X et al. Genital human papillomavirus infection among women recruited for routine cervical cancer screening or for colposcopy determined by Hybrid Capture II and polymerase chain reaction. Diagn Mol Pathol 1999; 8: 157-64.

27 Munoz N, Bosch FX, Castellsague $X$ et al. Against which human papillomavirus types shall we vaccinate and screen? The international perspective. Int J Cancer 2004; 111: 278-85.
28 Johnson T, Bryder K, Corbet S, Fomsgaard A. Routine genotyping of human papillomavirus samples in Denmark. APMIS 2003; 111: 398-404.

29 Speich N, Schmitt C, Bollmann R, Bollmann M. Human papillomavirus (HPV) study of 2916 cytological samples by PCR and DNA sequencing: genotype spectrum of patients from the west German area. I Med Microbiol 2004; 53: 125-8.

30 Melchers WJ, Bakkers JM, Wang J et al. Short fragment polymerase chain reaction reverse hybridization line probe assay to detect and genotype a broad spectrum of human papillomavirus types. Clinical evaluation and follow-up. Am J Pathol 1999; 155: 1473-8.

31 Verteramo R, Pierangeli A, Calzolari E et al. Direct sequencing of HPV DNA detected in gynaecologic outpatients in Rome, Italy. Microbes Infect 2006; 8 (9-10): 2517-21.

32 Beerens E, Van Renterghem L, Praet $M$ et al. Human papillomavirus DNA detection in women with primary abnormal cytology of the cervix: prevalence and distribution of HPV genotypes. Cytopathology 2005; 16: 199-205.

33 Clifford GM, Gallus S, Herrero Ret al. World wide distribution of human papillomavirus types in cytologically normal women in the International Agency for Research on Cancer HPV prevalence surveys: a pooled analysis. Lancet 2005; 366: 991-8. 